\title{
Differences in characteristics between people with lower limb amputations who died before 12 weeks and those who survived: Short Report
}

ABSTRACT: The baseline determinants of survival following a non-traumatic lower limb amputation (LLA) in participants in the Johannesburg metropolitan area are unknown.

The aim of the study was to establish the characteristics of participants who had died by three months after LLA

A longitudinal pre-test- post test study utilized participant interviews $(n=73)$. Consecutive sampling was used to select participants who met the inclusion criteria.

Ethical clearance was obtained. Permission was obtained from the hospitals. Participants gave consent before taking part in the study.

A demographic questionnaire, the EQ-5D, the Modified Household Economic and Social Status Index (HESSI) and the Barthel Index (BI) were used, to collect data.

Participants were interviewed preoperatively and then followed up three months post-operatively to establish survival/ existence.

Twenty-four participants (33\%) had died. The preoperative median Visual Analogue Scale (VAS) of the EQ-5D was 60 and 70 showing no significant difference in quality of life (QOL) between those who survived and those who died respectively. The preoperative median total BI score was 20 and 19 showing significantly inferior function for the deceased $(p=0.01)$. The deceased were significantly older $(p=0.009)$ used alcohol $(p=0.02)$ and smoked tobacco $(p=0.03)$.

Being older, having poorer function, being a smoker and drinking alcohol preoperatively seem to decrease the chance of survival following LLA in Johannesburg.

KEY WORDS: LOWER LIMB AMPUTATION, SURVIVAL, QUALITY OF LIFE, FUNCTION, SOCIOECONOMIC STATUS.

\section{INTRODUCTION}

Lower limb amputation (LLA) results in a wide range of outcomes including death (Leung and Wong, 2004). Survival rates vary across countries but the mortality rate is generally high (Wong, 2005; de Godoy et al, 2005). Old age and higher anatomical levels of ampu-

\section{Correspondence to:}

Lonwabo L Godlwana

Department of Physiotherapy

School of Therapeutic Sciences

Faculty of Health Sciences

University of the Witwatersrand

7 York Road, Parktown

Johannesburg,

South Africa

E-mail: lonwabo.godlwana@wits.ac.za tation are associated with poor survival. Mortality in LLA has been reported as early as the perioperative stage, where $14.7 \%$ of participants with diabetes and $21.3 \%$ of participants without diabetes tend to die (Papazafiropoulou et al, 2009).

Mortality rates of $12 \%$, and $29 \%$, at one week, and 30-days respectively have also been reported (Eskelinen et al, 2004). Back-Pettersson and Bjorkelund (2005) reported that, one third of participants died within six months regardless of gender and age.

In South Africa, there is no literature on mortality following LLA.This paper therefore describes the differences in function, quality of life and socioeconomic characteristics between those patients with amputations who sur- vived and those who had died before a 12 week follow up which was part of a larger study on patients with lower limb amputation. The results of this study may assist in improving current pre and postoperative management interventions for people with LLA.

\section{METHODOLOGY}

This was a longitudinal pre and post test study conducted between 01 June 2008 to 01 June 2009. Participants were interviewed preoperatively and then traced to verify their existence 12 weeks post operatively. Consecutive sampling was used to draw participants $(n=73)$ from the preoperative lists of people scheduled for first time major LLA at the three tertiary hospitals in Johannesburg. Participants were excluded if their 
amputation was as a result of trauma or a congenital birth defect; if they had co-morbidities that interfered with function pre-operatively, and that could potentially impact on their recovery and those with altered cognitive function making it difficult for them to comprehend the study and thus, the nature of participation.

Institutional ethical approval was obtained and participants gave informed consent. A pilot study was conducted to ensure understanding of the questionnaires used to collect data. Three well known valid and reliable questionnaires were used to collect data in addition to a basic demographic questionnaire, namely, the Modified HESSI (Barbarin and Khomo, 1997) the EQ-5D and the Barthel Index (BI) (Finch, 2000).

All data were obtained using interviews. Baseline data were collected pre-operatively when patients were admitted to hospital for the amputation. The second set of data collection was done post-operatively 12 weeks after the amputation.

Data were analyzed using STATA 10.0. Data are presented as means, standard deviations, medians and frequencies. Preoperative differences were analyzed using the Wilcoxon Signed-rank test and Chi square/Fischer's exact tests.

\section{RESULTS}

Seventy- three participants were eligible for the study. Forty (55\%) participants survived, 9\% were lost during follow up and $33 \%(n=24)$ were confirmed as deceased.

Participants who died were significantly older than those who survived $(\mathrm{p}=0.009)$.

\section{Summary of clinical characteristics}

Forty-six percent of the deceased group had hypertension, 67\% diabetes, 50\% reported peripheral vascular disease $40 \%$ chronic heart diseases. Other clinical conditions, included renal failure, presence of a retroviral disease and oncology (13\%).

Sixty percent of the surviving group had hypertension, 64\% diabetes, $48 \%$ peripheral vascular disease $1 \%$ chronic heart diseases. Other clinical conditions reported, (16\%) included renal failure, presence of a retroviral disease and oncology.
A significantly higher percentage of participants who smoked died $(p=0.03)$ as did those who drank alcohol $(\mathrm{p}=0.02)$.

The people who died were generally of poorer functional status than those who survived as seen by the median total BI scores $(\mathrm{p}=0.01)$.

There was no significant difference in the EQ-5D median VAS score between the two groups $(p=0.4)$ and no significant differences in the EQ-5D item scores for the two groups.

Table 1: Comparison of demographic characteristics of the survivors $(n=40)$ and the deceased $(n=24)$

\begin{tabular}{|c|c|c|c|}
\hline & Preoperatively & Preoperatively & \multirow[t]{2}{*}{ p-value } \\
\hline & $\mathrm{n}=40$ (Survivors) & $n=24$ (Deceased) & \\
\hline \multicolumn{3}{|l|}{ Gender } & \\
\hline Male & $n=27(67.5 \%)$ & $\mathrm{n}=17(70.8 \%)$ & \\
\hline Female & $n=13(32.5 \%)$ & $\mathrm{n}=7(29.2 \%)$ & \\
\hline \multicolumn{3}{|l|}{ Race } & \\
\hline Black & $\mathrm{n}=30(75 \%)$ & $n=14(58.3 \%)$ & \\
\hline White & $\mathrm{n}=5(12.5 \%)$ & $n=8(33.3 \%)$ & \\
\hline Indian & $\mathrm{n}=0(0 \%)$ & $n=1(4.2 \%)$ & \\
\hline Coloured & $\mathrm{n}=5(12.5 \%)$ & $\mathrm{n}=1(4.2 \%)$ & \\
\hline \multicolumn{3}{|c|}{ Level of Amputation } & \\
\hline Unilateral BKA & $n=26(65 \%)$ & $n=13(54.2 \%)$ & \\
\hline Unilateral AKA & $n=14(35 \%)$ & $n=11(45.8 \%)$ & \\
\hline \multirow[t]{2}{*}{ Age } & $\begin{array}{l}\text { Mean }(S D) \text { and } \\
\text { percentiles }(n=40)\end{array}$ & $\begin{array}{l}\text { Mean (SD) and } \\
\text { percentiles }(n=24)\end{array}$ & \multirow[t]{2}{*}{0.009} \\
\hline & $\begin{array}{l}\text { Mean } 52.9 \text { SD8.61 } \\
47-25^{\text {th }} \\
52-50^{\text {th }} \\
58.5-75^{\text {th }}\end{array}$ & $\begin{array}{l}\text { Mean } 58.54 \text { SD7.27 } \\
52-25^{\text {th }} \\
59-50^{\text {th }} \\
63.5-75^{\text {th }}\end{array}$ & \\
\hline
\end{tabular}

Table 2: Comparison of social habits for the survivors $(n=40)$ and deceased participants $(n=24)$

\begin{tabular}{|l|l|l|l|}
\hline \multirow{2}{*}{ Social habits } & Preoperatively & Preoperatively & \multirow{2}{*}{ p-value } \\
\cline { 2 - 3 } & $\mathrm{n}=\mathbf{4 0}$ (Survivors) & $\mathrm{n}=\mathbf{2 4}$ (Deceased) & \\
\hline Use of alcohol & & & \\
\hline Yes & $\mathrm{n}=21(52.5 \%)$ & $\mathrm{n}=9(37.5 \%)$ & \multirow{2}{*}{0.02} \\
\hline No & $\mathrm{n}=19(47.5 \%)$ & $\mathrm{n}=15(62.5 \%)$ & \\
\hline Smoking & & & \\
\hline Yes & $\mathrm{n}=21(52.5 \%)$ & $\mathrm{n}=10(41.7 \%)$ & \multirow{2}{*}{0.03} \\
\hline No & $\mathrm{n}=19(47.5 \%)$ & $\mathrm{n}=14(58.3 \%)$ & \\
\hline
\end{tabular}

Household Economic and Social Status

In the deceased group, 58\% were married and currently living with their partners. The remainder of the participants were either never married and not living with a partner $(17 \%)$, married but not living with a partner $(8 \%)$ e.g. divorced or separated, widowed (13\%) and never married but living with a partner (4\%). In this group, $21 \%$ had no income. Those who had an income were receiving private pensions $(4 \%)$, old 
age pensions $(25 \%)$, disability grants (12\%), and 38\% were still employed. Only one participant lived in a shack and $61 \%$ lived in a home that was not shared with other families.

In the survivors group, $43 \%$ of the participants were married and living with their partners. The remaining participants were either never married and not living with a partner (15\%), married but not living with a partner $(18 \%)$ e.g. divorced or separated, widowed $(12 \%)$ and never married but now living with a partner $(12 \%)$. Forty percent of the surviving participants had no income. Those who had an income received a private pension $(2 \%)$, old age pension $(18 \%)$, a disability grant $(10 \%)$, and (30\%) were employed. The level of education ranged from no formal education to college education. One participant was homeless, $18 \%$ lived in shacks and $50 \%$ lived in a home that was not shared with other families.

\section{DISCUSSION}

Thirty-three percent $(n=24)$ of participants died before three months. Generally, LLA has a high mortality rate. Research shows that the survival rate varies across countries (de Godoy et al, 2005; Nehler et al, 2003). None of these studies were conducted in Africa but there was a high mortality rate in a study done in Brazil, which is a developing country like South Africa (de Godoy etal, 2005). The above studies had follow ups ranging from two weeks postoperatively to five years postoperatively.

The deceased group had significantly more smokers than those who survived. Current smoking is a significant predictor of death from cardiac causes in people with LLA (Davis et al,2006). Similarly, the group who died had significantly more drinkers than those who survived. Naschitz and Lenger (2008) report that moderate alcohol consumption (drinking) has a cardiovascular protective effect, however, an increased risk of cardiovascular related death isobserved among heavy drinkers. The amount of alcohol drunk by participants was not recorded but possibly due to higher levels of smoking and drinking, people may have had poorer cardiovascular function and this resulted in death.

The participants who died were gene-
Table 3: Comparison of functional status between the participants who survived $(n=40)$ and those who died $(n=24)$

\begin{tabular}{|c|c|c|c|}
\hline Item Score & $\begin{array}{l}\text { Preoperative } \\
\mathrm{n}=40(100 \%) \\
\text { (Survivors) }\end{array}$ & $\begin{array}{l}\text { Preoperative } \\
\mathrm{n}=24(100 \%) \\
\text { (Deceased) }\end{array}$ & p-value \\
\hline \multicolumn{4}{|l|}{ Bl-Bowel } \\
\hline 0 & $\mathrm{n}=0(0 \%)$ & $\mathrm{n}=0(0 \%)$ & \multirow{3}{*}{0.008} \\
\hline 1 & $\mathrm{n}=0(0 \%)$ & $\mathrm{n}=4(16.7 \%)$ & \\
\hline 2 & $\mathrm{n}=40(100 \%)$ & $\mathrm{n}=20(83.3 \%)$ & \\
\hline \multicolumn{4}{|l|}{ BI-Bladder } \\
\hline 0 & $\mathrm{n}=0(0 \%)$ & $\mathrm{n}=0(0 \%)$ & \multirow{3}{*}{0.04} \\
\hline 1 & $\mathrm{n}=1(2.5 \%)$ & $\mathrm{n}=4(16.7 \%)$ & \\
\hline 2 & $\mathrm{n}=39(97.5 \%)$ & $\mathrm{n}=20(83.3 \%)$ & \\
\hline \multicolumn{4}{|l|}{ BI-Grooming } \\
\hline 0 & $\mathrm{n}=0(0 \%)$ & $\mathrm{n}=1(4.2 \%)$ & \multirow{2}{*}{ NS } \\
\hline 1 & $\mathrm{n}=40(100 \%)$ & $\mathrm{n}=23(95.8 \%)$ & \\
\hline \multicolumn{4}{|l|}{ BI-Toilet use } \\
\hline 0 & $\mathrm{n}=0(0 \%)$ & $\mathrm{n}=1(4.2 \%)$ & \multirow{3}{*}{ NS } \\
\hline 1 & $\mathrm{n}=5(12.5 \%)$ & $\mathrm{n}=4(16.7 \%)$ & \\
\hline 2 & $\mathrm{n}=35(87.5 \%)$ & $\mathrm{n}=19(79.2 \%)$ & \\
\hline \multicolumn{4}{|l|}{ BI-Feeding } \\
\hline 0 & $\mathrm{n}=0(0 \%)$ & $n=1(4.2 \%)$ & \multirow{3}{*}{ NS } \\
\hline 1 & $\mathrm{n}=0(0 \%)$ & $n=1(4.2 \%)$ & \\
\hline 2 & $\mathrm{n}=40(100 \%)$ & $\mathrm{n}=22(91.6 \%)$ & \\
\hline \multicolumn{4}{|l|}{ BI-Transfer } \\
\hline 0 & $n=1(2.5 \%)$ & $n=1(4.2 \%)$ & \multirow{4}{*}{0.03} \\
\hline 1 & $\mathrm{n}=2(5 \%)$ & $\mathrm{n}=4(16.7 \%)$ & \\
\hline 2 & $\mathrm{n}=1(2.5 \%)$ & $\mathrm{n}=4(16.7 \%)$ & \\
\hline 3 & $\mathrm{n}=36(90 \%)$ & $\mathrm{n}=15(62.4 \%)$ & \\
\hline \multicolumn{4}{|l|}{ BI-Mobility } \\
\hline 0 & $\mathrm{n}=2(5 \%)$ & $n=1(4.2 \%)$ & \multirow{4}{*}{0.001} \\
\hline 1 & $\mathrm{n}=1(2.5 \%)$ & $\mathrm{n}=4(16.7 \%)$ & \\
\hline 2 & $\mathrm{n}=0(0 \%)$ & $n=5(20.8 \%)$ & \\
\hline 3 & $\mathrm{n}=37(92.5 \%)$ & $\mathrm{n}=14(58.3 \%)$ & \\
\hline \multicolumn{4}{|l|}{ BI-Dressing } \\
\hline 0 & $\mathrm{n}=0(0 \%)$ & $\mathrm{n}=0(0 \%)$ & \multirow{3}{*}{0.02} \\
\hline 1 & $\mathrm{n}=1(2.5 \%)$ & $\mathrm{n}=5(20.8 \%)$ & \\
\hline 2 & $\mathrm{n}=39(97.5 \%)$ & $\mathrm{n}=19(79.2 \%)$ & \\
\hline \multicolumn{4}{|l|}{ BI-Stairs } \\
\hline 0 & $\mathrm{n}=4(10 \%)$ & $n=5(20.8 \%)$ & \multirow{3}{*}{ NS } \\
\hline 1 & $\mathrm{n}=3(7.5 \%)$ & $\mathrm{n}=5(20.8 \%)$ & \\
\hline 2 & $\mathrm{n}=33(82.5 \%)$ & $\mathrm{n}=14(58.4 \%)$ & \\
\hline \multicolumn{4}{|l|}{ BI-Bathing } \\
\hline 0 & $\mathrm{n}=1(2.5 \%)$ & $\mathrm{n}=3(12.5 \%)$ & \multirow{2}{*}{ NS } \\
\hline 1 & $\mathrm{n}=39(97.5 \%)$ & $\mathrm{n}=21(87.5 \%)$ & \\
\hline \multirow[t]{2}{*}{ Total BI } & $\begin{array}{l}\text { Mean }(S D) \text { and per- } \\
\text { centiles }(n=40)\end{array}$ & $\begin{array}{l}\text { Mean (SD) and } \\
\text { percentiles }(n=24)\end{array}$ & \multirow[t]{2}{*}{0.01} \\
\hline & $\begin{array}{l}\text { Mean } 19.15(S D 2.19) \\
19.5-25^{\text {th }} \\
20-50^{\text {th }} \\
20-75^{\text {th }}\end{array}$ & $\begin{array}{l}\text { Mean 16.92 } \\
(\text { SD3.91) } \\
13.5-25^{\text {th }} \\
19-50^{\text {th }} \\
20-75^{\text {th }}\end{array}$ & \\
\hline
\end{tabular}

NS-not significant, $p=0.05$ significant 
rally older than those who survived. A finding supported by Back-Pettersson and Bjorkelund (2005) and Otiniano et al (2003). The participants who died had poorer function compared to those who survived, which is similar to Otiniano et al (2003) Leung and Wong, (2004). Poor preoperative mobility and low preoperative BI scores are predictors of death (Leung and Wong, 2004). The poorer function in those who died may have meant that secondary complications due to immobility post operatively occurred, resulting in death. It was not possible to establish the level or availability of rehabilitation so without any interventions those participants with poor pre-operative function would probably have been fairly immobile post operatively.

The death rate in this study is double the figures reported in the literature (Papazafiropoulou et al (2009), Pernot et al (2000), Eskelinen et al (2004), Leung and Wong (2004). Eskelinen et al (2004) reported $29 \%$ deaths in 30 days, but the mean age was 72 years, 10 years older than those in this study. Papazafiropoulou et al (2009) only reported such findings at one to two year post operatively and, their participants were also 10 years older. Again this may be due to the poor mobility which in turn is probably due to a lack of accessible rehabilitation.

Most participants in both groups were single, they were of low socioeconomic status and the majority were males, a finding similar to Godlwana et al (2008). Participants were generally unemployed as were those of Burger and Marincek (2007), Amosun et al (2005). They were generally of low or had no formal education and this results in difficulty getting employment, which contributes to their poor economic status (Burger and Marincek, 2007). In turn this makes accessing rehabilitation difficult.

\section{CONCLUSION}

Death after LLA in Johannesburg is associated with poor preoperative function, smoking, drinking and being older. The Johannesburg Metropolitan area of South Africa appears to have a higher death rate following non-traumatic LLA within three months than that in other studies. Because these participants come from poor socio-economic backgrounds

Table 4: Comparison of the EQ- 5D VAS between the participants who survived $(n=40)$ and those who died $(n=24)$

\begin{tabular}{|l|l|l|l|}
\hline \multirow{3}{*}{ VAS } & \multicolumn{1}{|c|}{$\begin{array}{c}\text { Mean (SD) and } \\
\text { percentiles for } \\
\text { Survivors(n=40) }\end{array}$} & $\begin{array}{r}\text { Mean (SD) and } \\
\text { Percentiles for } \\
\text { Deceased(n=24) }\end{array}$ & p-value \\
\cline { 2 - 3 } & Mean $62.88(S D 22.12)$ & Mean 67.5 (SD24.14) & \\
\cline { 2 - 3 } & $50-25^{\text {th }}$ & $50-25^{\text {th }}$ & \multirow{2}{*}{$0.4(\mathrm{NS})$} \\
\cline { 2 - 3 } & $60-50^{\text {th }}$ & $70-50^{\text {th }}$ & \\
\cline { 2 - 4 } & $80-75^{\text {th }}$ & $85-75^{\text {th }}$ & \\
\hline
\end{tabular}

a more concerted effort should be made to increase the accessibility of appropriate rehabilitation services. In addition the need for lifestyle modification programmes is evident.

\section{ACKNOWLEDGEMENTS}

The authors would like to extend a special thanks to Mr. Lesley Phokontsi, the Faculty Research Fund, Wits physiotherapy staff, Dr. Jarek Kowalczyk and his team, the Vascular Units and their respective General Surgery Units and the Physiotherapy Departments of the candidate hospitals for their support. Most importantly, we thank the participants for taking part in this study.

\section{REFERENCES}

Back-Pettersson S and Bjorkelund C 2005 Care of elderly lower limb amputees, as described in medical and nursing records. Scandinavian Journal of Caring Science 19: 337-343

Barbarin O, Khomo N, 1997 Indicators of economic status and social capital in South African townships, what do they reveal about the material and social conditions in families of poor children? Childhood, 4(2): 193-222

Burger H and Marincek C 2007 Return to work after lower limb amputation. Disability and Rehabilitation 29(17): 1323-1329

Davis WA, Norman PE, Bruce DG, Davis TME 2006 Predictors, consequences and cost of diabetes-related lower extremity amputation complicating type 2 diabetes: The Fremantle Diabetes Study. Diabetologia 49: 2634-2641

De Godoy JMP, De Godoy MF, Batigalia F, Travolo ARF, Monteiro EHF 2005 Lowerextremity amputation: a 6-year follow-up study in Brazil. Journal of Orthopaedic Surgery 13(2): 164-166

Eskelinen E, Lepantalo M, Hietala EM, Sell H, Kauppila L, Maenpaa I, Pitkanen J, SalminenPeltola P, Leutola S, Eskelinen A, Kiviola A, Tukiainen E, Lukinmaa A, Brasken P, Railo M 2004 Lower extremity amputations in Finland in 2000 and trends up to 2001. European Journal of Vascular and Endovascular Surgery 27(2): 193-200
Finch E, Brooks D, Stratford PW, Mayo NE, 2002 Physical rehabilitation outcome measures, a guide to enhance clinical decision making, $2^{\text {nd }}$ edition: 87-89, 125-129, Lippincott Williams\& Wilkins

Godlwana L, Nadasan T, Puckree T 2008 Global trends in incidence of lower limb amputation: A review of the literature. South African Journal of Physiotherapy 64(1): 8-11

Leung HB, and Wong WC 2004 Preoperative and rehabilitation outcome after lower-limb amputation in elderly Chinese patients in Hong Kong. Journal of Orthopaedic Surgery 12(1): 102-109

Naschitz JE, and Lenger R 2008 Why traumatic amputees are at increased risk for cardiovascular diseases. Oxford Journal: Q J Med: An International Journal of Medicine 101: 251-259

Nehler MR, Coll JR, Hiatt WR, Regensteiner JG, Schickel GT, Klenke WA, Strecker PK, Anderson MW, Jones DN, Whitehill TA, Moskowitz S, Krupski WC 2003 Functional outcomes in a contemporary series of major lower amputations. Journal of Vascular Surgery 38(1): 7-14

O'Hare AM, Feinglass J, Reiber GE, Rodriquez RA, Daley J, Khuri S, Henderson WG, Johansen KL 2004 Postoperative mortality after nontraumatic lower extremity amputation in patients with renal insufficiency. Journal of the American Society of Nephrology 15: 427-434

Otiniano ME, Du X, Ottenbacher K, Black SA, Markides KS 2003 Lower limb amputations in diabetic Mexican American elders incidence, prevalence and correlates. Journal of Diabetes and its Complications 17: 59-65

Papazafizopoulou A, Tentolouris N, Soldatos R-P, Liapis CD, Dounis E, Kostakis AG, Bastounis E, Katsilambros N 2009 Mortality in Diabetic and nondiabetic amputations performed from 1996 to 2005 in a tertiary hospital population: a 3 year follow-up study. Journal of Diabetes and its Complications 23:7-11

Pernot HFM, Winnubst GMM, Cluitmans JJM, De Witte LP 2000 Amputees in Limburg: incidence, morbidity and mortality, prosthetic supply, care utilization and functional level after one year. Prosthetics and Orthotics International 24(2): 90-96

Wong MWN 2005 Lower extremity amputation in Hong Kong. Hong Kong Medical Journal 11(3): 147-152 